\title{
5-Fluorouracil for the treatment of intraepithelial neoplasia and squamous cell carcinoma of the conjunctiva, and cornea
}

This article was published in the following Dove Press journal:

Clinical Ophthalmology

15 July 2010

Number of times this article has been viewed

\author{
Abdulmoghni Al-Barrag' \\ Mutahar Al-Shaer' \\ Nabil Al-Matary ${ }^{2}$ \\ Mohammed Al-Hamdani ${ }^{2}$ \\ 'Ophthalmic Department, Faculty of \\ Medicine and Health Sciences, Sana'a \\ University, Sana'a, Republic of Yemen; \\ ${ }^{2}$ Ophthalmic Department, Military \\ Hospital, Sana'a, Republic of Yemen
}

Objective: To evaluate the efficacy and risks of complications of pulse dosing of topical 5-fluorouracil (5-FU) in the treatment of corneal intraepithelial neoplasia (CIN), and conjunctival squamous cell carcinoma (SCC).

Design: Prospective, noncomparative case series.

Participants: Fifteen patients with histological evidence CIN or SCC of the conjunctiva and cornea were identified by tumor biopsy.

Methods: All patients clinically evident of CIN, or SCC were evaluated, with maximum 30 months of follow-up were treated with pulsed dosing of $1 \% 5$-FU. Treatment cycles were defined as four times per day for 4 days using the medication followed by 30 days without medication. The number of initial treatment was six cycles.

Results: The mean age of the 15 patients was 50.8 years (range 25-78 years). Excision biopsy proved seven cases as CIN, and eight cases as locally invasive SCC. All patients remained disease free with a mean follow-up of 14.53 months (range 6-30 months). Additional chemotherapy was given after the initial treatment cycles, only for one case. 5-FU caused mild temporary local irritation, but no long-term intraocular or extra ocular complications.

Conclusions: Adjuvant 1\% topical 5-FU appears to be effective in the prevention of recurrence of conjunctival or corneal CIN and SCC after excision biopsy. Our results indicate that at least six cycles of topical $1 \% 5-\mathrm{FU}$ is required to prevent local recurrence in the long term. It is well-tolerated and an effective method of treatment. No complications that would preclude use of our dose regimen were noted.

Keywords: chemotherapy, fluorouracil, neoplasia, treatment cycles

\section{Introduction}

Conjunctival intraepithelial neoplasia (CIN) is a frequent conjunctival tumor, while squamous cell carcinoma is the most frequent malignant tumor of the conjunctiva. ${ }^{1-6}$ Early manifestation is a small mass mimicking pterygium growing at or around the limbus, occurring in middle-aged patients. ${ }^{2-4}$

Following excision alone recurrences are frequent. Effective postsurgical recurrence prevention is therefore highly desirable. The primary treatment modality for this lesion is wide local excision and supplemental cryotherapy, with accurate histological assessment of the surgical margins..$^{3-5}$ However, the recurrence rate is still high, even when surgical margins of primary excision are free from malignant cells. ${ }^{7}$ Moreover, recurrences may be multiple and their occurrence greatly increases the risk of local spread. ${ }^{8}$ Local irradiation is sometimes used in conjunction with repeated excision to treat conjunctival recurrences of squamous cell carcinoma. ${ }^{9-10}$ However, side effects limit the use of supplemental irradiation.
Correspondence: Abdulmoghni

OAl-Barrag

Faculty of Medicine and Health Sciences, Sana'a University, PO Box I 1820 (The old University Zone) Sana'a, Yemen

Tel +967- I-503728

Mobile+967-7777I5584

Email al_barrag@yahoo.com 
Topical conjunctival chemotherapy with antineoplastic drugs has recently been proposed as a new approach in the treatment of conjunctival premalignant lesions, (primary acquired melanosis and conjunctival intraepithelial neoplasia) with promising results. ${ }^{11-21} \beta$-irradiation, ${ }^{9}$ topical urea, ${ }^{10}$ and immunotherapy, ${ }^{11}$ have been shown to reduce recurrence rates. Topical interferon- $\alpha-2 b$ has also been proposed as a possible medical alternative to surgical excision of primary or recurrent intraepithelial neoplasia. ${ }^{12}$ Topical chemotherapeutic agents, including topical mitomycin C (MMC), and 5-fluorouracil (5-FU), have been shown to be effective in treating conjunctival and corneal intraepithelial neoplasia alone, or as an adjunct to surgical excision, ${ }^{1,13-19}$ Although topical 5-FU has been shown to be effective in treating CIN, we propose an alternative dosing regimen that is as effective, better tolerated, and has reduced adverse side effects as compared with previous reported dosing regimens. ${ }^{17-19}$

\section{Patients and methods}

In this study we took biopsies from the conjunctival and corneal masses followed by application of topical 5-FU to evaluate the efficacy, and prevention of recurrence of CIN and SCC. Seven patients with histological confirmed CIN, and eight patients with SCC were treated with $1 \%$ topical 5-FU. In this study, we defined conjunctival intraepithelial neoplasia, as any degree of basal layers of epithelial dysplasia (ie, mild, moderate, and severe), including the full epithelial thickness involvement (carcinoma in situ) without any evidence of invasion. Squamous cell carcinoma was defined as when there is invasion to the conjunctival stroma.

The clinical data included patient age, race, gender, eye involved, tumor extent, and initial management. At the time of examination, data collection included visual acuity, tumor location, conjunctival quadrant involved, and extent of involvement on the conjunctival and corneal surfaces, based on clinical and histopathological evidence. Tumor features of vascularity, nodularity, and leukoplakia were recorded. All patients were negative for HIV test as a precipitating factor especially in the young. The mean age of this group of patients was 50.8 years, ranging from 25 to 78 years. All patients were of Arabic origin. Three males and twelve females; the right and left eyes were involved in nine and six patients respectively.

Inclusion criteria included patients presenting with conjunctival and corneal tumors, proved histopathologically as cases of CIN or SCC. Exclusion criteria included patients, with conjunctival or corneal tumors other than CIN or SCC. Patients with AIDS and xeroderma pigmentosum were excluded from the study.
At presentation, the tumor involved the limbus and cornea in all 15 eyes, forniceal conjunctiva in one eye, and no tarsal conjunctival involvement. Excision biopsy was obtained in all patients from the thickest portion of the tumor. Disease involvement varied from 2.5 to 9 clock hours of the limbus; 1.5 to $8 \mathrm{~mm}$ of extension into clear cornea; and $9 \mathrm{~mm}$ of extension into the bulbar conjunctiva. In fourteen eyes, the bulbar conjunctiva was freely mobile. One patient whose lesion was firmly affixed to the underlying tissues (Table 1, patient 9) topical 5-FU was prescribed after surgical biopsy. 5 -fluorouracil (5-FU) was prepared by the resident to be given subconjunctivally using 25 -gauge needle as $5 \mathrm{mg}$ immediately at the end of the surgery.

Eight patients were affected by conjunctival squamous cell carcinoma (four recurrent cases), one case (Table 1, patient 7) recurrent after excision. Patients 10,11 and 14 had recurrence twice after surgery. Seven cases were diagnosed as CIN. All patients received pulse dose of 1\% 5-FU eye drops. The topical chemotherapy was administered four times daily for 4 days for six treatment cycles with 30 days interval between the cycles.

Each patient had excision biopsy of the tumor when a diagnosis of conjunctival or corneal epithelial tumor was suspected. The $1 \% 5$-FU therapeutic agent was prepared, and given by subconjunctival injection using 25 -gauge needle as $5 \mathrm{mg}$ immediately at the end of the surgery. In fourteen eyes the bulbar conjunctiva was freely mobile. One patient the lesion was firmly affixed to the underlying tissues. Patching the eye was done for 24 hours postoperatively. In the first postoperative visit four patients had some necrotic tissues over the excised tumor. The necrotic tissue was removed using wet cotton bud with $1 \% 5$-FU (prepared eye drops). This application was repeated for two to three days. All patients used the prepared 1\% 5-FU eye drops four times a day for four days then repeated at 30 day intervals for six cycles. The $1 \% 5-\mathrm{FU}$ therapeutic agent was prepared using polyvinyl alcohol and povidone solution as the vehicle. The medication bottle was returned to the pharmacy after each cycle of use.

Patient report, Table 1, No.7; A 47-year-old white female was evaluated for a conjunctival lesion of her right eye after recurrence of the lesion. The lesion was diagnosed earlier as pterygium. Excision of the mass was done for the second time. Her visual acuity was $1 / 60$ in the right eye and $6 / 18$ in the left eye without correction. The right eye showed a limbal mass involving approximately $270^{\circ}$ of the corneoscleral limbus that extended $6 \mathrm{~mm}$ into the corneal surface. No preauricular or cervical lymphadenopathy was detected. Histological examination of multiple conjunctival biopsies 


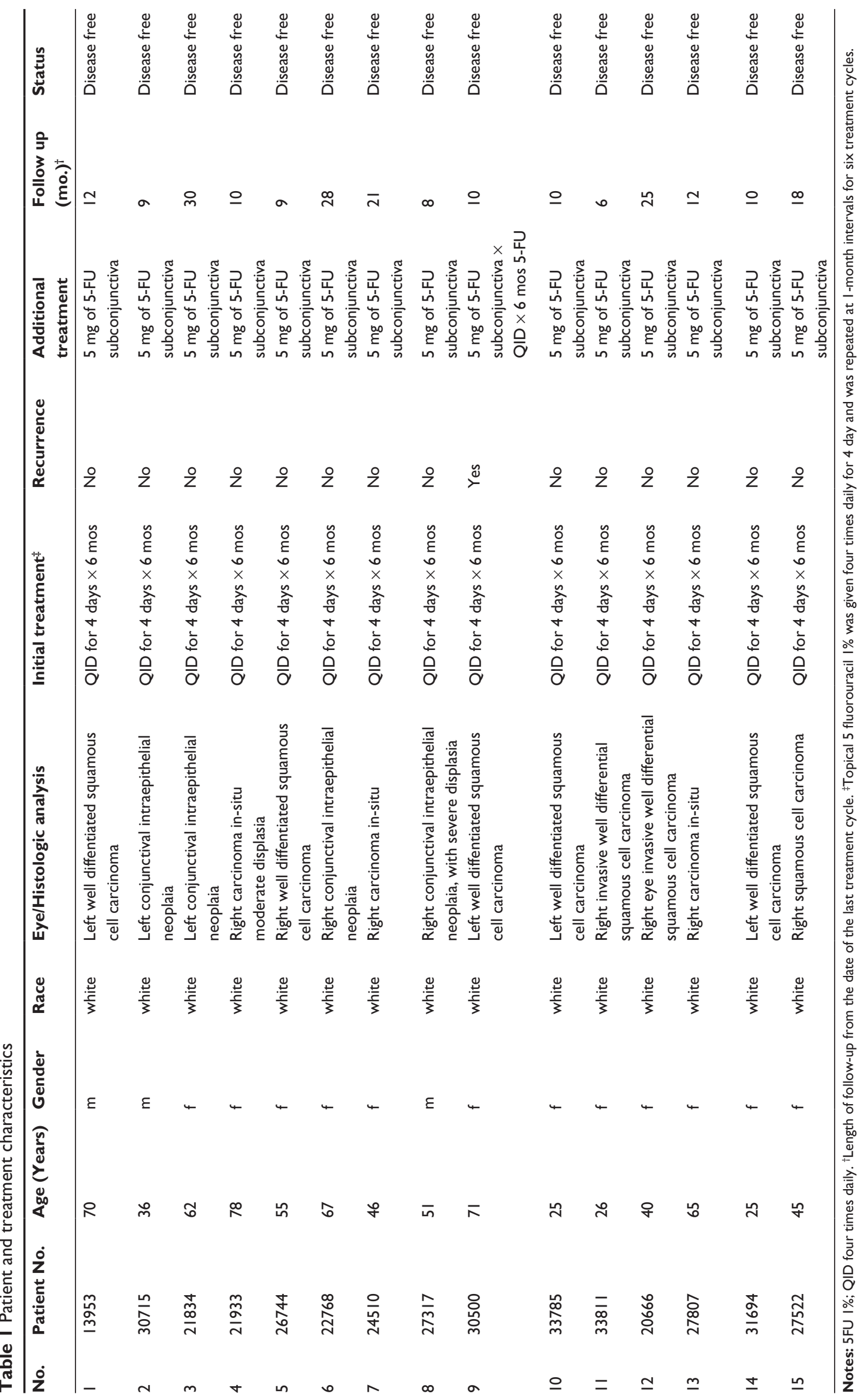


showed carcinoma in-situ. Five milligrams of 5-FU was given in the subconjunctival tissues after biopsy was taken. The patient was treated with $1 \%$ topical 5 -FU four times daily for 4 days, for six treatment cycles. The necrotic tissue on first and second day postoperatively was removed by sterile wet cotton bud with prepared $1 \% 5$-FU eye drops. There was clinically no evidence of recurrence for 21 months after the final treatment cycle. SPSS software (version 13; SPSS Inc., Chicago, IL) was used to analyze some data such as mean of the age, and the time of the follow-up of this study.

Patient report, Table 1 No.15, A 45-year-old white female was referred for application of 5-FU $1 \%$ eye drops for her recurrent conjunctival squamous cell carcinoma. Excision of the mass in another ophthalmic department was done three times, with rapid recurrence of the tumor; histopathology was diagnosed as squamous cell carcinoma of the conjunctiva. She received mitomycin C $0.02 \%$ as eye drops after the diagnosed four times for four days for two cycles. Recurrences of the tumor, for the fourth time, led her treating ophthalmologist to refer her to our department. We managed the case by the subconjunctival $5 \mathrm{mg}$ of 5 -FU for two days after removal of the tumor and confirming the diagnoses for the fifth time as squamous cell carcinoma of the conjunctiva. She received the regular treatment of 5-FU $1 \%$ eye drops for six cycles. The patient was clinically free from the tumor after 18 months of follow up.

During treatment, symptomatic side effects of the medication were recorded by the patients in a daily diary. Ocular examination was performed daily in the first week, and then at 1, 2, 3, 4, 5, and 6 months following treatment, then twice yearly thereafter. Clinical examination (slit-lamp biomicroscopy and photography) and morphological evaluation of conjunctival cytological specimens were used to monitor the efficacy of local chemotherapy, side effects, and recurrences. During the last clinic visit the visual acuity, tumor status, globe status, and systemic status were assessed. The main outcome measures were tumor control and medicationrelated toxicity. The presence or absence of clinically evident CIN, and SCC were evaluated after each treatment interval. Patients were also monitored for adverse reactions to the use of topical 5-FU.

\section{Results}

Ten patients were treated with $1 \%$ topical 5 -FU for histological confirmed as squamous cell carcinoma of the conjunctiva, cornea, or both. The other five patients' histopathology was diagnosed as conjunctival and corneal intraepithelial neoplasia. The mean follow-up time was 14.53 months (range 6-30 months).
The results are summarized in Table 1, while all the tumors were responsive to topical 1\% 5-FU treatment. Most of the patients had resolution of the tumor, after the initial series of treatments, and required no additional 5-FU after six cycles.

One of these patients (Table 1; patient 11) is still under treatment. She is going on the last cycle with regular follow up. The second patient (Table 1; patient 8) received the last cycle two months ago and has had regular follow up with no recurrence. The third patient (Table 1, patient 15) had three recurrences after simple excision. After the third excision she received MMC $0.02 \%$ eye drops two cycles four times per day for four days of treatments in another ophthalmic department, continued to have early recurrence of the disease despite treatment. In our department with many times of recurrence, we put her on topical 5-FU for six cycles at monthly intervals with resolution of the tumor. The patient has remained free of recurrence for 12 months after the last treatment cycle. Another, one very old female patient (Table 1, patient 9) with tumor fixed to the sclera had partial excision of the tumor in another ophthalmic department, and was diagnosed by histopathology as squamous cell carcinoma of the conjunctiva. She was referred for initial treatment of 5-FU. Recurrence occurred after 5 months of the final treatment. This patient was given second additional cycles of topical 1\% 5-FU to eradicate the disease at monthly intervals for six cycles. The patient has remained tumor-free for the ten months of observation after the second series of treatment.

Figure 1A shows the appearance of recurrent bulky conjunctival mass at presentation, with a chronic inflammatory infiltrate (Table 1 , patient 7 ). The tumor involving $270^{\circ}$ of the corneoscleral limbus was successfully treated without the appearance of limbal stem cell deficiency. The visual acuity at presentation was counting fingers at one meter, improved to $6 / 24$ without correction after the eradication of the tumor. Histopathology confirmed the diagnosis as carcinoma in-situ of the conjunctiva. Figures $1 \mathrm{~B}$ and $1 \mathrm{C}$ shows the appearance of the eye after three and five treatment cycles respectively. Although this patient received topical steroid to reduce the ocular irritation and inflammation associated with the use of chemotherapy, is now tumor free for 21 months of follow-up.

Figure $2 \mathrm{~A}$ shows a dramatic response to $1 \% 5-\mathrm{FU}$ (Table 1, patient 8). Histological analysis showed intraepithelial neoplasia of the conjunctiva, with severe dysplasia. Figure 2B shows the appearance of the eye after six treatment cycles. 


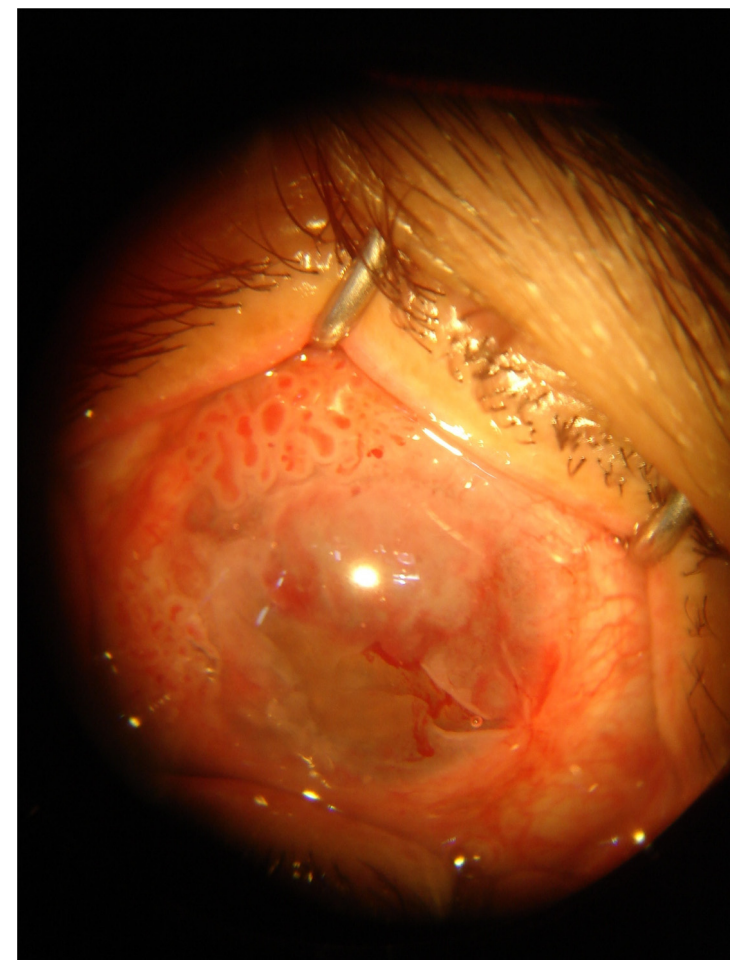

Figure IA Extensive carcinoma in-situ at the time of presentation, involving most of the bulbar conjuctiva, imparting a gelatinous appearance to the conjunctiva and camouflaging the conjuctival vessels.

Figure $3 \mathrm{~A}$ shows differentiated squamous cell carcinoma of the conjunctiva that was proved by histopathology seen at presentation (Table 1, patient 14). Figure 3B shows the appearance of the tumor was completely eradicated by the treatment of 5-FU $1 \%$ at the seven months of follow up.

\section{Discussion}

The management of conjunctival and corneal CIN and SCC continues to evolve. ${ }^{21,24-26}$ Until recently, surgical excision

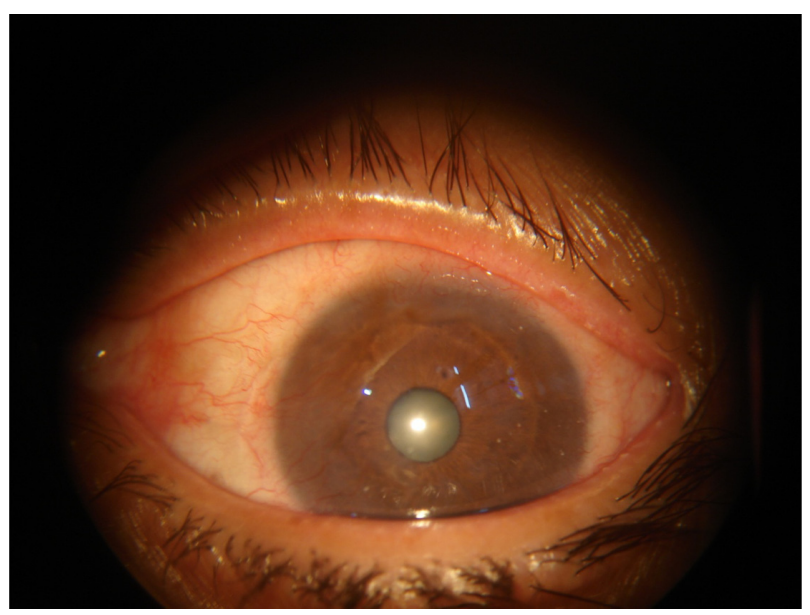

Figure IB Appearance of the eye 3 months after the initial treatment cycle with topical 5-FU.

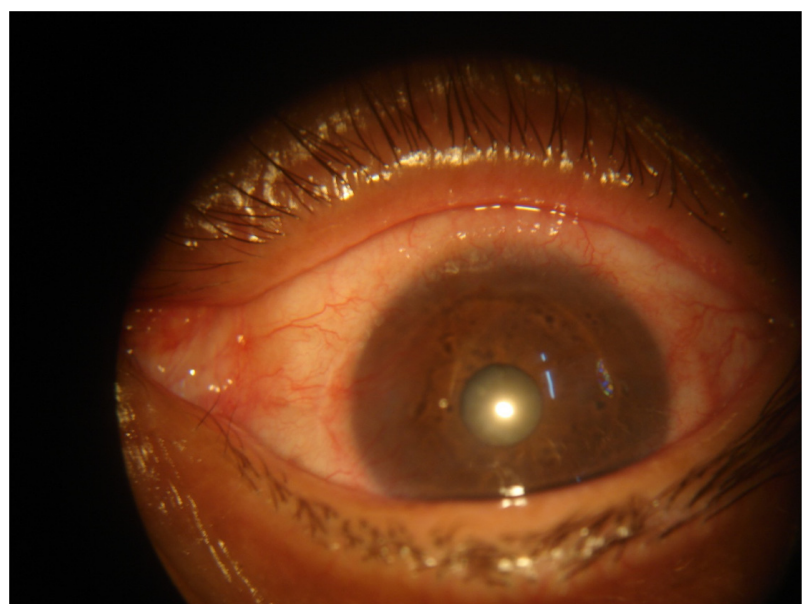

Figure IC Appearance of the eye 5 months after the initial treatment cycle with topical 5-FU.

and cryotherapy of the conjunctival mass combined with alcohol corneal epitheliectomy were the main treatment strategies. ${ }^{27}$ Because most of these tumors arise at or near the limbus, extensive surgical excision or cryotherapy risks the development of limbal stem cell deficiency. Complete surgical removal of these tumors would have been difficult and would have likely resulted in obvious ocular surface scarring, like tissue granulation, pseudopterygium and symblepharon. Also diplopia from tissue foreshortening, blepharoptosis and other complications that can result from the healing process were often bothersome to the patient. Furthermore, the possibility that during the surgical procedure, some tumor cells may be reimplanted and cause recurrence of a neoplastic process, cannot be excluded. Additionally, tumor recurrence of approximately $30 \%$ following surgical resection has been reported. ${ }^{28}$ These problems have stimulated clinicians to investigate alternative treatments. Chemotherapy

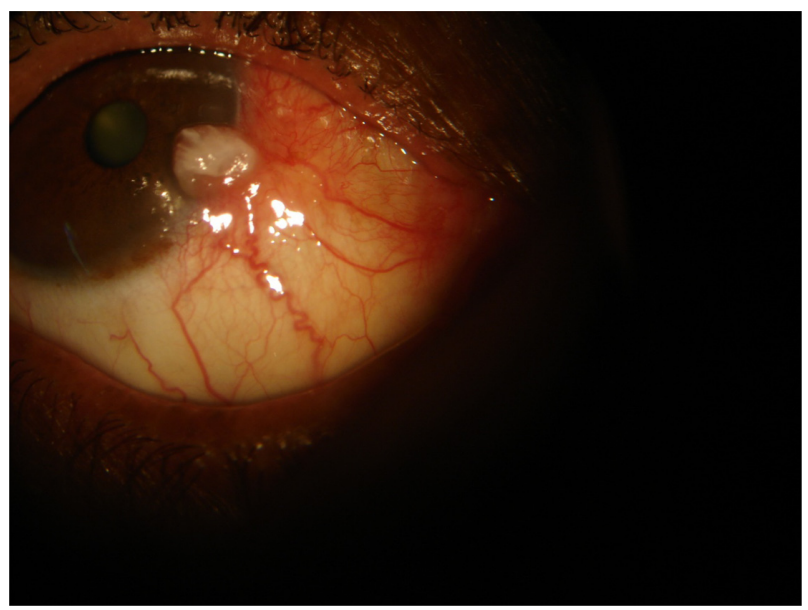

Figure 2A Right conjunctival intraepithelial neoplasia, with severe dysplasia at presentation. 


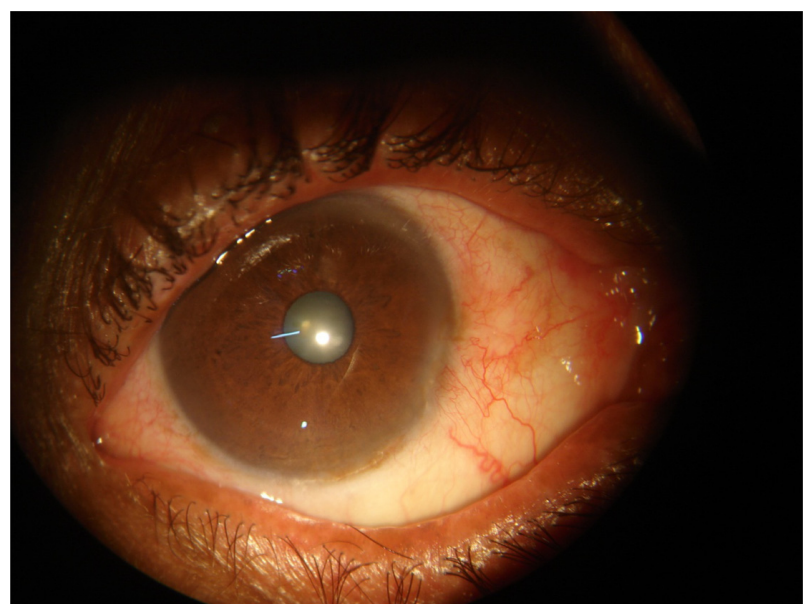

Figure 2B Right eye appearance after 6 months of 5-FU.

with topical 5-FU had some advantages over the surgical approach. It does not rely on histological identification of the lesion, and it eradicates the histological, nonvisible nest of neoplastic cells. Chemotherapy spares the surrounding normal tissue, which is usually excised around the lesion. No limbal stem cell deficiency noted in patients treated with topical chemotherapy alone. Furthermore, patients prefer treatment with application of the drops rather than surgery. On the other hand, the chemotherapeutic treatment is longer, requires close follow-up and compliant patients, and may cause adverse reactions.

Because of the high recurrence rate and technical difficulties associated with surgical excision, many methods of treatment for $\mathrm{CIN}$ have been investigated. ${ }^{29-39} \beta$-Irradiation, ${ }^{29}$ topical chemotherapy, ${ }^{31-43}$ and immunotherapy ${ }^{17,30}$ have been used as an adjunct or alone in treatment of CIN. De Keizer et $\mathrm{al}^{34}$ first described the use of topical 5-FU in the treatment of premalignant lesions of the cornea, conjunctiva, and eyelid. Yeatts et al ${ }^{35-36}$ corroborated the effectiveness of 5-FU; subsequently, other investigators reported the use of $\mathrm{MMC}$ alone or as an adjunct to surgical excision in treatment

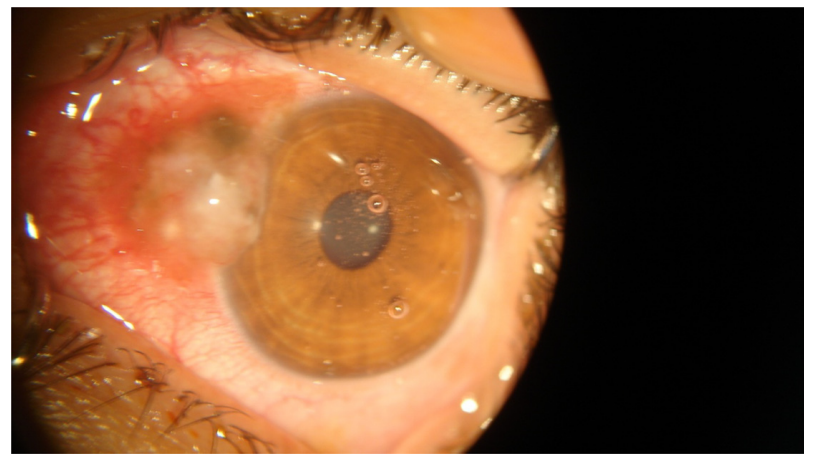

Figure 3A Left eye, well diffentiated squamous cell carcinoma at presentation.

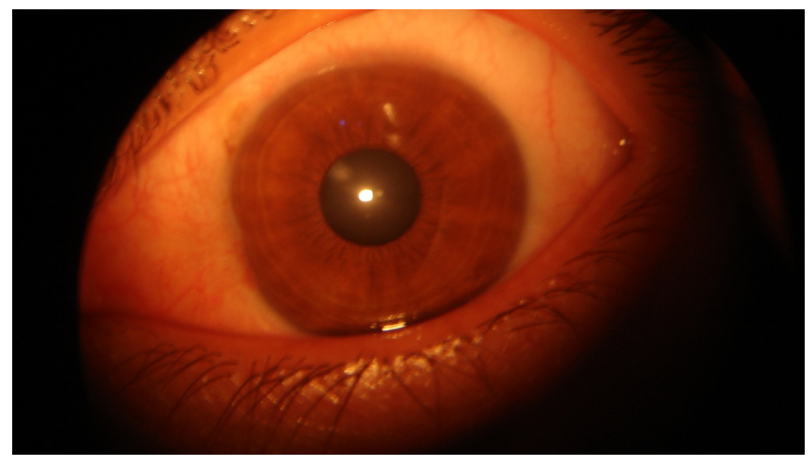

Figure 3B Left eye, appearance after four months treatment by 5 -FU.

of CIN. ${ }^{31-33,42}$ Current treatment regimens involve topical administration of 5-FU or MMC four times daily for 1 to 2 weeks. ${ }^{30-34}$ One or more side effects are observed in almost all patients and include: conjunctival and corneal inflammation; corneal epithelial defects and the associated pain; and, eyelid skin erythema, irritation, and discomfort.

The role of topical 5-FU in the treatment regimen of CIN and SCC appears promising. Administering the 1\% 5-FU four times daily but limiting the dose duration to 4 days with repeat cycles every 30 days for four to six cycles appears to be as efficacious as a longer dose period of 7 to 14 days, and without the adverse side effects. ${ }^{34-36}$ Thus, multiple treatment exposures may be required to expose all tumor cells to the chemotherapeutic agent during the time of their maximal susceptibility. The number of treatment cycles required to eradicate CIN is unknown. ${ }^{38}$

Topical chemotherapy is not recommended as a single or solitary treatment of invasive squamous cell carcinoma of the cornea and conjunctiva. The potential failure of penetration of a topical chemotherapeutic agent limits its role in invasive disease. ${ }^{36-37}$ However, topical therapy may play a useful role in reducing the tumor size and eliminating intraepithelial disease, thereby limiting the subsequent excision to the smaller invasive component.

Topical chemotherapy has several advantages when compared with the traditional surgical excision and cryotherapy. ${ }^{34,43}$ The potential advantages include: treatment of the entire ocular surface, thereby eliminating the need to ensure clear tissue margins, as is necessary with surgical excision; apparent targeting of the tumor cells, reducing the risk of limbal stem cell deficiency associated with more destructive therapies involving the limbus; simplicity of treatment and reduced patient cost associated with avoidance of the surgical area; and reduced patient morbidity. Although the recurrence rate of CIN in patients treated with topical chemotherapy is unknown, treatment of the entire ocular 
surface may theoretically reduce recurrent disease associated with focal destructive procedures. ${ }^{38}$

Toxicity to the lacrimal drainage apparatus was reported with topical 5 -FU, ${ }^{40}$ but not observed in any patient in this study. Some patients developed skin irritation, but no experience of conjunctival injection, keratopathy, with our treatment regime. Some of our patients required additional treatment like dexamethasone eye drops to control the inflammatory reaction. One patient was given additional treatment cycle of $1 \% 5$-FU due to early recurrence, and remained tumor free after ten months follow up. In such cases, other chemotherapeutic drugs can be used instead of MMC. ${ }^{35-36,40}$ Both topical interferon and topical 5-FU were reported as alternative treatments for MMC. Only one report indicated efficacy of topical interferon for CIN. ${ }^{35-36}$ A small number of CIN cases were successfully treated with topical 5-FU. ${ }^{40}$ Larger series of cases with long-term follow-up and comparative studies are required to consider topical 5-FU as an alternative to MMC.

Maskin, ${ }^{40}$ investigating the presence of HPV in neoplastic and non-neoplastic disorders of the external eye, detected evidence of HPV by the polymerase chain reaction in 57\% of patients with carcinoma in situ of the conjunctiva, $55 \%$ of patients with invasive squamous cell carcinoma, $35 \%$ of patients with scarred corneas, and in $32 \%$ of patients with normal conjunctival tissue obtained at cataract surgery.

The proper approach to presumed CIN lesions requires histological diagnosis by excisional biopsy for small lesions and incisional biopsy for large lesions before further treatment is considered. ${ }^{21,41}$ Impression cytology, brush or scraping for histologic diagnosis of the conjunctival cells also may be useful. We believe that the general ophthalmologist, with limited clinical experience to intraepithelial lesions, should use one of the diagnostic measures before prescribing 5FU. However, an experienced expert in the field of cornea or ocular tumors who clinically diagnoses a small-size growing CIN with typical leukoplakia may use a topical chemotherapy based on clinical impression, particularly in patients who refuse any surgical approach, and those who can comply with the treatment and be easily monitored.

This study suggests that, treatment of corneal and conjunctival intraepithelial neoplasia, and squamous cell carcinoma with pulse doses of topical $1 \% 5$-FU four times daily for 4 days, with repeat treatment cycles at monthly intervals for six cycles, is effective in treating CIN, and SCC, with no demonstrable side effects. Retreatment is required when the lesion recurs, and excisional biopsy should be done when the treatment fails. Long-term follow-up is required in these patients, as CIN lesions may recur years after the treatment.

\section{Acknowledgments}

We would specially thank all ophthalmic surgeons, who did the work, including the theatre nurses in the ophthalmic department, Sana'a University. We appreciate the critical comments and linguistic advice of Prof Mahfouth Bamashmus and finally we thank Prof Talal Haider the head of the department for his support.

\section{Disclosure}

The authors report no conflict of interest in this work

\section{References}

1. Lovieno A, Lambiase A, Moretti C, et al. Therapeutic effect of topical 5-fluorouracil in conjunctival squamous carcinoma is associated with changes in matrix metalloproteinases and tissue inhibitor of etalloproteinases expression. Cornea. 2009;28:821-824.

2. McLean IW, Burnier MN, Zimmerman LE, et al. Tumors of the Eye and Ocular Adnexa. 3rd series. Washington, DC: Armed Forces Institute of Pathology, 1994:49-95.

3. Pe'er J. Ocular surface squamous neoplasia. Ophthalmol Clin North Am. 2005;18:1-13.

4. Shields CL, Demirci H, Karatza E, et al. Clinical survey of 1643 melanocytic and nonmelanocytic conjunctival tumors. Ophthalmology. 2004;111:1747-1754.

5. Shields CL, Shields JA. Tumors of the conjunctiva and cornea. Surv Ophthalmol. 2004;49:3-24.

6. Shields JA, Shields CL, De Potter P. Surgical management of conjunctival tumors. Arch Ophthalmol. 1997;115:808-815.

7. Erie JC, Campbell RJ, Liesegang TJ. Conjunctival and corneal intraepithelial and invasive neoplasia. Ophthalmology. 1986;93:176-183.

8. Tabin G, Levin S, Snibson G, et al. Late recurrences and the necessity for long-term follow-up in corneal and conjunctival intraepithelial neoplasia. Ophthalmology. 1997;104:485-492.

9. Lommatzsch PK. Beta-ray treatment of malignant epithelial tumors of the conjunctiva. Am J Ophthalmol. 1976;41:198-206.

10. Lommatzsch PK. Conjunctival tumors and their radiotherapy. In: Alberti WE, Sagerman RH, editors. Radiotherapy of Intraocular and Orbital Tumors. Berlin: Springer-Verlag, 1993; Chapter 25.

11. Midena E, Angeli CD, Valenti M, et al. Treatment of conjunctival squamous cell carcinoma with topical 5-fluorouracil. Br J Ophthalmol. 2000;84:268-272.

12. Karp CL, Moore JK, Rosa RH Jr. Treatment of conjunctival and corneal intraepithelial neoplasia with topical interferon alpha-2b. Ophthalmology. 2001;108:1093-1098.

13. Frucht-Pery J, Rozenman Y. Mitomycin C therapy for corneal intraepithelial neoplasia. Am J Ophthalmol. 1994;117:164-168.

14. Yeatts RP, Ford JC, Stanton CA, et al. Topical 5-fluorouracil in treating epithelial neoplasia of the conjunctiva and cornea. Ophthalmology. 1995;102:1338-1344.

15. Frucht-Pery J, Pe'er J. Use of mitomycin C in the treatment of conjunctival primary acquired melanosis with atypia. Arch Ophthalmol. 1996;114:1261-1264.

16. Frucht-Pery J, Sugar J, Baum J, et al. Mitomycin C treatment for conjunctival-corneal intraepithelial neoplasia: multicenter experience. Ophthalmology. 1997;104:2085-2093.

17. Wilson MA, Hungerford JL, George SM, et al. Topical mitomycin C for the treatment of conjunctival and corneal epithelial dysplasia and neoplasia. Am J Ophthalmol. 1997;124:303-311. 
18. Heigle TJ, Stulting RD, Palay DA. Treatment of recurrent conjunctival epithelial neoplasia with topical mitomycin C. Am J Ophthalmol. 1997;124:397-399.

19. de Keizer RJW, DeWolff-Rouendaal D, Van Delft JL. Topical application of 5-fluorouracil in premalignant lesions of cornea, conjunctiva and eyelid. Doc Ophthalmol. 1986;64:31-42.

20. Finger PT, Milner MS, McCormick SA. Topical chemotherapy for conjunctival melanoma. Br J Ophthalmol. 1993;77:751-753.

21. Grossniklaus HE, Aaberg TM Sr. Mitomycin C treatment of conjunctival intraepithelial neoplasia. Am J Ophthalmol. 1997;124:381-383.

22. Ferry AP, Meltzer MA, Taub RN. Immunotherapy with dinitrochlorobenzene (DNCB) for recurrent squamous cell tumor of the conjunctiva. Trans Am Ophthalmol Soc. 1977;74:154-171.

23. Vann RR, Karp CL. Perilesional and topical interferon alfa-2b for conjunctival and corneal neoplasia. Ophthalmology. 1999; 106:91-97.

24. Waring GO 3rd, Roth AM, Ekins MB. Clinical and pathological description of 17 cases of corneal intraepithelial neoplasia. Am J Ophthalmol. 1984;97:547-559.

25. Fraunfelder FT, Wingfield D. Management of intraepithelial conjunctival tumors and squamous cell carcinomas. Am J Ophthalmol. 1983; 95:359-363.

26. Peksayar G, Soytürk MK, Demiryont M. Long-term results of cryotherapy on malignant epithelial tumors of the conjunctiva. Am JOphthalmol. 1989;107:337-340.

27. Shields JA, Shields CL, De Potter P. Surgical management of conjunctival tumors: the 1994 Lynn B. McMahan Lecture. Arch Ophthalmol. 1997;115:808-815.

28. Lee GA, Hirst LW. Ocular surface squamous neoplasia. Surv Ophthalmol. 1995;39:429-450

29. Lommatzsch P. Beta-ray treatment of malignant epithelial tumors of the conjunctiva. Am J Ophthalmol. 1976;81:198-206.

30. Danopoulos ED, Danopoulou IE, Liarikos SB, et al. Effects of urea treatment in malignancies of the conjunctiva and cornea. Ophthalmologica. 1979;178:198-203.
31. Heigle TJ, Stulting RD, Palay DA. Treatment of recurrent conjunctival epithelial neoplasia with topical mitomycin C. Am J Ophthalmol. 1997; 124:397-399.

32. Haas K, Ben-Dor D, Levartovsky S. Treatment of conjunctival corneal intraepithelial neoplasia with topical mitomycin C. Arch Ophthalmol. 1999;117:544-545.

33. Akpek EK, Ertoy D, Kalayci D, et al. Postoperative topical mitomycin C in conjunctival squamous cell neoplasia. Cornea. 1999;18:59-62.

34. de Keizer RJW, de Wolff-Rouendaal D, van Delft JL. Topical application of 5-fluorouracil in premalignant lesions of cornea, conjunctiva and eyelid. Doc Ophthalmol. 1986;64:31-42.

35. Yeatts RP, Engelbrecht NE, Curry CD, et al. 5-Fluorouracil for the treatment of intraepithelial neoplasia of the conjunctiva and cornea. Ophthalmology. 2000;107:2190-2195.

36. Yeatts RP, Ford JG, Stanton CA, et al. Topical 5-fluorouracil in treating epithelial neoplasia of the conjunctiva and cornea. Ophthalmology. 1995; 102:1338-1344

37. Midena E, Boccato P, Angeli CD. Conjunctival squamous cellcarcinoma treated with topical 5-fluorouracil. Arch Ophthalmol. 1997; 115:1600-1601.

38. Yeatts RP, Engelbrecht NE, Curry CD, et al. 5-Fluorouracil for the treatment of intraepithelial neoplasia of the conjunctiva and cornea, Ophthalmology. 2000;107:2190-2195.

39. Shapiro MS, Thoft RA, Friend J, et al. 5-Fluorouracil toxicity to the ocular surface epithelium. Invest Ophthalmol Vis Sci. 1985;26:580-583.

40. Maskin SL. Regression of limbal epithelial dysplasia with topical interferon. Arch Ophthalmol. 1994;12:1145-1146.

41. Smolin G, Thoft RA. The Cornea. 3rd ed. Boston, MA: Little, Brown, 1995:579-595.

42. Shields CL, Naseripour M, Shields JA. Topical nitomycin C for extensive, recurrent conjunctival-corneal squamous cell carcinoma. Am J Ophthalmol. 2002;133:601-606.

43. Yamamoto N, Ohmura T, Suzuki H, et al. Successful Treatment with 5-Fluorouracil of Conjunctival Intraepithelial Neoplasia Refractive to Mitomycin-C Ophthalmology. 2002;109:249-252.
Clinical Ophthalmology

\section{Publish your work in this journal}

Clinical Ophthalmology is an international, peer-reviewed journal covering all subspecialties within ophthalmology. Key topics include: Optometry; Visual science; Pharmacology and drug therapy in eye diseases; Basic Sciences; Primary and Secondary eye care; Patient Safety and Quality of Care Improvements. This journal is indexed on

\section{Dovepress}

PubMed Central and CAS, and is the official journal of The Society of Clinical Ophthalmology (SCO). The manuscript management system is completely online and includes a very quick and fair peer-review system, which is all easy to use. Visit http://www.dovepress.com/ testimonials.php to read real quotes from published authors. 